\title{
THE PLACE OF ANATOMY IN THE MEDICAL CURRICULUM
}

\author{
By D. C. Sinclair, M.A., M.D. \\ Professor of Anatomy, University of Western Australia; late University Demonstrator in Human Anatomy, Oxford
}

Anatomy is an old punching bag for cliniciansthey wrote letters to the Lancet about it fifty years ago, just as they do today, complaining that students know no anatomy and that the subject must therefore be badly taught. Anatomists are a stolid race, but this continued assault has induced in some of them a mild anxiety state, a certain diffidence about their subject. Like all departments through which the medical student passes, the anatomy department has its faults, but I believe that diffidence in relation to the teaching of anatomy in Britain is unjustified, and that some at least of the criticisms levelled against it arise from misconceptions of the part anatomy has to play in the education of a modern doctor.

In a recent article Singer (1954) pointed out that it is only for the last 400 years or so that we have come to regard anatomy as the foundation of medical education. Nevertheless, the idea is now so firmly established that the British medical student invariably encounters anatomy at the-very beginning of his preclinical career: the foundations must be laid before the rest of the building can be erected. This preclinical anatomy accounts for most of his education in the subject, but in the clinical period there are classes in applied anatomy, particularly in relation to surgery. For many this completes the study of anatomy, but the graduate who wants to specialize in surgery, gynaecology, anaesthetics, etc., must pass a further examination in anatomy, and this may drive him back into an anatomy department for a period to revise and extend his anatomical knowledge.

\section{Preclinical anatomy}

The General Medical Council stipulates (1947), that the preclinical period of a student's education should last not less than five terms, and that in this time anatomy, physiology (including biochemistry), and the elements of psychology should be studied. Since in Britain anatomy and physiology are always taught concurrently and not successively, it follows that the anatomy course is spread over a minimum of five terms (sometimes six). At the end of this period the student faces an examination in anatomy and physiology; he must take both subjects together, and in London he has also to cope with pharmacology.

By 'anatomy' in this context the General Medical Council means:

I. The dissection of the whole body

2. The anatomy of the living body, including its radiological examination

3. Histology

4. Elements of human embryology

Two further prescribed subjects are often taught in the anatomy department, though it is not precisely laid down that this is to be so. They are:

5. Elements of genetics

6. The use of instruments employed in diagnosis (with demonstrations on the living subject).

This is a large and varied programme for five terms of study. In British medical schools in 1953 physiology and biochemistry took an average of 560 hours out of these terms (Sinclair, 1955), leaving the anatomy department with an average of 960 hours, (the scatter around this mean is perhaps rather startling, for it extends from about 700 hours to over 1,400 hours). What does the student do in these 960 hours? He spends about 100 of them on histology, 55 on neuroanatomy, and 45 on embryology; in consequence 760 hours are left for topographical anatomy, including living and radiological anatomy. This time includes lectures and demonstrations, revision classes, tutorials and so on, but the bulk of it is allotted to practical dissection.

This, then, is the average British procedure. What do we expect the student to get out of it? What is the use of anatomy to the doctor, as opposed to the specialist? The writer of a recent letter to the British Medical Journal said, in effect, that he had found anatomy extremely useful because it involved such an appalling amount of hard work that afterwards he did not even notice the rigours of general practice. It is possible, therefore, that anatomy has a value as a discipline, in the ecclesiastical sense of the word as a mortifier of the 
flesh. There is, however, more than this. Anatomy demands a great many qualities which are essential to every doctor-the student is required to be thorough and methodical; he has to be neat and precise with his fingers, and he has to learn to pay attention to detail. His memory, by being continually called on, extends its range and power. Slowly and painfully he acquires the habit of exactness in speech. He begins to say what he means, and becomes able to frame an orderly and logical description of what he sees. Some, of course, never attain to these heights, but those clinicians who complain that their students are woolly-minded should see them when they are beginning the study of anatomy.

Anatomy also acts as an invaluable ball and chain to physiology. Physiologists are, as a class, prone to armchair speculation, and often find a way out of their functional difficulties by inventing anatomical explanations. I might perhaps illustrate what I mean by reference to the peripheral nervous system. In 1940 there were five distinct systems of nerves in the skin, four of which had been postulated by physiologists to serve their own needs. The fact that the anatomist could not and can not distinguish more than one system of nerves has been a useful drag on the student's enthusiam, and the number of functional systems is steadily decreasing. As van Gudden once said 'Always let us have anatomy first, or if physiology must come first, then never without anatomical control.'

Finally, anatomy provides the student with a store of technical information. It is this aspect of the subject that arouses the most ill-feeling. The non-anatomist, with his eyes on the vast spread of time allotted to anatomy, claims that far too much time is spent on teaching. far too much detail (I should here point out in parenthesis that 'details' are always what somebody else teaches). The simplest answer to this criticism is the rather sterile ' $t u$ quoque.' Is it any more reprehensible to teach the student the ossification of the upper end of the humerus on the chance that he may one day encounter a suspected fracture in this region than it is to teach the symptoms and signs of Rocky Mountain spotted fever on the chance that he may one day go to the Rockies? Is the nerve supply of the scalene muscles really of less importance to the general practitioner than the chemical formula of progesterone? Are the branches of the inferior mesenteric artery so much waste material and the cultural characteristics of the cholera vibrio absolutely fundamental? It is not perhaps realized that since 1900 anatomists have reduced the amount of material taught to medical students by about a third in Britain and a half in America, and that the process of reduction is still going on fairly rapidly. How many other departments can say the same thing?

The golden days of topography have gone. At the end of the last century, when every man could be his own surgeon, every student was taught as an undergraduate enough anatomy to serve his needs in the operating theatre. Since then surgery has progressed too far for the non-specialist, and a prospective surgeon has to study anatomy all over again for his surgical diploma. In the circumstances it is a waste of time to teach first-year students enough topographical detail to fit them to become surgeons. Some people still argue that there is practically no anatomical fact which might not be useful to a general practitioner some day, but we are coming to agree that this is no valid reason for teaching every student every anatomical fact we can command. There is not, and will never be, agreement on what constitutes the basic fund of anatomy which every practitioner must know, and there is thus a considerable regional variation in the amount and kind of the material taught in anatomy departments-a variation which I personally find an extremely healthy sign.

Nevertheless, specialist clinicians continue to demand that we should knock out this and include that, and it may be salutary to consider the experience of Greulich (1953), who took these requests at the letter, and asked the clinicians each to enumerate the things they wanted taught to medical students by the anatomy department. He found that if all the requests were acted upon the course in anatomy would have had to be extended for one more year.

Local circumstances must determine to a certain extent the amount of detail taught. In Britain no patient is nowadays very far from a properly qualified surgeon in a properly appointed hospital, but in a country like Western Australia, in spite of the Flying Doctor service, it is still necessary for every doctor to know at least enough anatomy to be able to deal with accidents and surgical emergencies.

Critics of the long period spent in British dissecting rooms should remember that the average figure of 760 hours for topography is a negative rather than a positive one; it merely represents the amount of time during which the dissecting room is open and the student has no other officially appointed tasks. It is thus a maximum which is never attained by any given student. $\mathrm{He}$ has, after all, other things to do. He has his elevenses and afternoon tea to think of, his football, his girl friend. He is harrassed by class examinations administered by other departments. I should guess (it is no more than a guess) that very few students use more than two thirds of the available time for the study of topography. It is often pointed out 
that in America topography occupies only some 300-400 hours in the curriculum. But the American student is a couple of years older, and takes his whole medical course much more seriously. For him to examine a dead body is frequently a privilege rather than an imposition. The hours available for dissection in American syllabuses are thus more nearly a minimum than a maximum, for in many places the dissecting room is open in the evenings and enthusiastic students work far into the night.

At present we in Britain are bound by the recommendation (which has more or less the force of law) of the General Medical Council (1947), that the student shall dissect the whole body. Now dissecting the whole body is a leisurely process, for practical anatomy differs in the important factor of atmosphere from practical biochemistry or physiology. Physiologists and biochemists are busy men with appointments to keep; the student gathers that they can spare him a couple of hours now and then to show him how to do an experiment. He turns up sharp on time, the experiment works or does not work, he observes the lab man hovering round waiting to clear away the apparatus, he goes away. Next day a different experiment is laid on. Nothing could be more businesslike or more precise; so much work done, so many results obtained. In the dissecting room the body waits patiently, the demonstrator strolls up and down or sits down to read the New Yorker; there is no urgency, no hurry. The use of cutting instruments is-as in the barber's shop and the operating theatre-conducive to conversation, and the student needs plenty of time for discussion and argument. Some students are slick, others are slow, and time must be allowed for the laggard to finish.

In some overseas dissecting rooms there is complete regimentation; students are signed in and signed out, and more or less dissect by numbers. This system certainly saves time, but I question whether the anatomy learned in this way is remembered so well as the anatomy discovered by the student's own endeavours, working at his own optimum rate, and allowing the features of his dissection to sink gradually into his mind. It is also suggested that to gain time it would be sufficient for the student to dissect one 'part' only, and that the rest of the body could be demonstrated to him in the form of prosected specimens. I personally do not agree with this idea because I think that the biggest trouble the student has in learning topography is the third dimension. He can only get things straight in his mind if he can constantly refer to his own ' part,' which he himself has carved out, like a sculptor, from the material provided, and which he himself can handle in his own way.

\section{Applied anatomy}

Most surgeons are shocked and horrified to find that, when the student comes to begin surgery, he cannot remember whether the appendix is on the right or the left side of the body, and that he believes the tonsil to be supplied by the vertebral artery. It is, of course, a truism that throughout the curriculum every department finds its new students arrive totally inadequately prepared by previous departments, but as I see it there are two main reasons why the student who got through the examination in anatomy reasonably well should become the stuttering moron who confronts the surgeon in his first clinic. One is the delay between leaving anatomy and beginning surgery, for this allows him to forget what he has learned before he comes to apply it. This factor is particularly relevant in Oxford, where the Honours School of Animal Physiology interposes an extra year between anatomy and surgery, so that the student's crop of anatomical information may lie unharvested for as much as $2 \frac{1}{2}$ years; it is perhaps little wonder that it is often found to have rotted in the interval.

The second reason is that those who teach anatomy have failed to put it across to the student that anatomy is a living rather than a dead subject, that it has immense practical applications, and that these must be remembered and used for the rest of his clinical career. Too often the student looks on the examination in anatomy as a culmination rather than a beginning, and he is often startled to realize that there is a continuity between the dissecting room and the hospital ward. This, I feel, is wholly wrong, and is the fault of the anatomists. Now that so few anatomists have much clinical experience it is undoubtedly difficult for them to point the clinical applications of topographical work, but much more effort could be put into this aspect of anatomical teaching.

It is because of the lack of clinical experience among anatomists that I hold strongly that applied anatomy should be taught by clinicians. It should never be treated as a separate subject done up in a little parcel which is opened at a given stage for a given time to display the wonders within; rather it should be insisted on as a factor permeating the whole of clinical work. Surgical anatomy is merely anatomy seen through the eyes of a surgeon; it is not a ' subject' but an attitude of mind. It is nowadays fashionable to stress the desirability of ' integrating' the preclinical subjects into a single composite structure. But the best clinical teachers have always integrated preclinical information to explain clinical conditions. This, after all, is what a clinical teacher is for.

\section{Postgraduate anatomy}

Many candidates for the Primary examination 
for the diploma of Fellow of the Royal College of Surgeons spend some time working in a preclinical department before offering themselves for examination, and the departments of anatomy and physiology to which they come find their presence most stimulating and useful. They are the teachers who are most capable of giving anatomy the clinical slant which is so often lacking, and who can best give the student the idea that what he is doing is vital and alive rather than dead and dispiriting.

A visitation of this kind is also useful in showing the candidate something of the atmosphere of a preclinical department and the methodology of research. Anatomy is nowadays an experimental subject, and most embryo clinicians would benefit greatly by an appreciation of its problems and techniques. The best way of learning a subject is to attempt to teach it to other people, and Primary candidates who take this road to their objective find anatomical demonstration an immense help. It might even be a good thing if the regulations for the Primary were worded so as to oblige candidates to work for a period as a demonstrator in a preclinical department.

Conversely, it would be equally desirable to insist that intending anatomists should have had some clinical experience before shutting themselves up in their preclinical eyrie. Unfortunately this is, for financial reasons, becoming less and less possible (Sinclair, 1955), and the anatomist of the future is likely to have a B.Sc. or a Ph.D., but no medical qualification.

\section{Experiments}

So far we have considered only the normal; let us now turn to what most would call the unusual, and possibly a few the pathological. In Britain we are at present rather strictly confined by the recommendations of the General Medical Council, and the scope of experiment is small indeed. Nevertheless, at Birmingham the preclinical curriculum has been reorganized so that the teaching of anatomy, physiology and biochemistry is presented as a unified whole. The lecture courses of the three departments are combined into one, and by avoiding overlap the total lecturing time has been substantially reduced. The practical classes have remained outside the scheme, and the dissecting-room teaching has been cut down from five terms to three, though there has been no reduction of the time spent in dissection. At the end of three terms the student sits an examination in topographical anatomy and histology, and in the remaining two terms the emphasis is placed mainly on physiology, neurology and living anatomy. The examination at the end of the fifth term deals mostly with these subjects, but a certain amount of topographical anatomy is also included.
Personally I am in hearty agreement with the idea that anatomy and physiology should be taught as a unified whole, and as far as possible in such a way as to lead the student to forget that they are labelled separate ' subjects.' I also believe that the student should be made to realize that anatomy does not suddenly stop being important as soon as he has passed his second M.B. examination. It might at first sight seem that these two objectives are mutually contradictory. On the one hand it is desirable that anatomy should be integrated with physiology at the very beginning of the curriculum, so that structure and function should combine to give the student an understanding of the normal body. On the other it would seem ideal that anatomy should immediately precede surgery, so that as short an interval as possible might separate the two subjects. There may, however, be some confusion here between two essentially separate divisions of anatomy.

General anatomy and histology are concerned with the study of the organization of tissues, and are essential to an understanding of physiology. Also essential for this purpose is the topographical anatomy of the brain and spinal cord, without which the functioning of the nervous system is impossible to visualize. General anatomy and neural topography must indeed come first, so that the students can appreciate their functional studies. But the second division of anatomy, the gross regional topography which is studied in the dissecting room, is mostly quite irrelevant to the study of physiology or biochemistry, though it is vital to the clinical disciplines. The relations of the radial nerve are not essential data for an understanding of neural transmission, but they are very necessary to a discussion on fractures of the humerus.

It appears, therefore, that it might be possible to separate one division of anatomy from the other, to have general anatomy, histology, and the study of the nervous system combined with the study of physiology and biochemistry in the earliest stages of the curriculum, and to postpone the dissecting room anatomy until much nearer the time when it needs to be applied. Considered in this light, the experiment at Birmingham appears to put the cart before the horse, for topography is studied in the early stages, and separated from clinical work by a greater interval than in the normal schedule. But is it in fact practical politics to cut off topographical anatomy from general anatomy and to teach it as a separate subject at a later stage in the curriculum? The experience gained. at Western Reserve University indicates that it probably is. In Western Reserve the preclinical curriculum is completely integrated. There is a general introduction dealing with the structure and activities of 
cells, and after this the various systems of the body are taken up, starting with locomotion and finishing with reproduction. Each system is taught by a committee drawn from the teachers whose subjects are most nearly concerned, irrespective of the departments to which they owe allegiance. Thus the committee dealing with the endocrine glands might comprise an anatomist, a physiologist, a pharmacologist, a biochemist and a clinician. During the period when the normal is being considered, topographical anatomy is kept to a minimum, and the student merely dissects roughly the appropriate regions of a still-born baby to satisfy himself of the general anatomical situation and appearance of the structures whose histology and function are being discussed. Most of the adult dissecting room work is delayed until the second year of his course, when the consideration of the abnormal has been introduced. In each system the normal anatomy is succeeded by the pathology, the pathological physiology, the clinical, microbiological and pharmacological aspects of the subject following in sequence. This means that normal gross anatomy is much more closely bound up with the clinical manifestations of disease-the student is likely to study the anatomy of the stomach in the morning, learn about its neoplasms in the afternoon, and see a patient with cancer of the stomach that same evening.

The Western Reserve experiment is a radical one, and the whole curriculum has been completely reorganized at the cost of immense labour. We need not necessarily contemplate anything so daring merely in order to move topographical anatomy a little closer to clinical work. We could, for example, simply reverse the Birmingham experiment, taking the physiology and general anatomy first and the topography second. Better, we might postpone the topography until after pharmacology and general pathology, which are both intimately bound up with histology and physiology. This would, of course, immediately encounter the obstacle of the anatomy/physiology examination prescribed by the General Medical Council at the end of the five preclinical terms, and it would be necessary for the Council to relax their grip slightly to permit of two examinations instead of one. The first would be in general anatomy and physiology, including histology, and the second one would be in topography, embryology, radiological and living anatomy. Western Reserve have met and overcome a similar obstacle in the shape of the National Board examinations in anatomy and physiology. I think there can be little doubt that the thing is possible, and may even be desirable, but I do not want to labour the point. I have brought it forward simply because at present the General Medical Council is being criticized by many people, including the Royal College of Physicians, for not permitting any individuality among medical schools, and it is quite likely that they may in the future decide to allow a little more latitude. It is therefore obviously desirable that we should think about the problems involved from every possible angle.

Perhaps I might sum up my own views-as a highly prejudiced party-by saying that I believe that anatomy in its present form is not so black as it is sometimes painted. I also believe that it could be better, and certainly this is so with regard to its relationship with the clinical subjects. A close liaison with surgery would be established if the habit of studying for the Primary Fellowship examination in departments of anatomy became universal, and another possible remedy might be the rearrangement of the position of anatomy in the curriculum, taking notice of the different affiliations of its component parts. One thing is certain; anatomy is at the moment in an active phase of adaptation to the changed conditions of medical practice. Modern anatomy is a very different subject from the anatomy of fifty years ago, and there is every likelihood that it may change still further, but I do not think that its importance in the curriculum will ever substantially diminish.

\section{BIBLIOGRAPHY}

GREULICH, W. W. (1953), Proc. Ist World Conference on Medical Education, p.231, London, Oxford University Press, r954.

"Recommendations as to the Medical Curriculum," London, The General Medical Council, 1947

SINCLAIR, D. C. (1955), "Medical Students and Medical Sciences," London, Oxford University Press.

SINGER, C. (1954), Brit. med. F., 2, I499-1 503. 